\title{
Keeping on track
}

\author{
The high points of collective ambition and achievement reached in Paris need nurturing to ensure results. \\ Maintaining momentum in climate action requires investment and ongoing commitment from all actors.
}

nternational ambition for climate action was at a high as the Paris Agreement was reached in late 2015 - agreement had not only been achieved but exceeded most expectations, with an ambitious temperature target of limiting global warming to $1.5^{\circ} \mathrm{C}$ above pre-industrial levels. This target, much lower than the commonly discussed $2{ }^{\circ} \mathrm{C}$ target, was promoted by the Least Developed Countries and Small Island Developing States (SIDS), and was a welcome surprise after previous failings to secure agreement; most recently on the Kyoto Protocol ${ }^{1}$.

Commitments were made with intended nationally determined contributions (INDCs) put forward and ratification of the Agreement a year later. However, the political landscape changed in the following months and Donald Trump's announcement that the United States was withdrawing from the Paris Agreement, of which the anniversary has just passed, was an early stumbling block to the new-found international unity.

Cities, states and local authorities can and are stepping up in place of national action, as a result of a more general groundswell of support. This process is occurring all over the world, and also manifests in the communities themselves leading the action, showing direction for their elected officials - be it through protesting fossil fuel projects ${ }^{2}$ or taking the initiative to raise funds for community renewable energy projects, which can support the transition to a low-carbon economy and empower the communities.

It is still early days but these first few years are crucial in cementing ongoing commitment and ensuring that the foundations are laid to achieve such targets. The Talanoa Dialogue, launched in November 2017 at the Bonn COP that was hosted by the SIDS, is proposed as a facilitative discussion to assist countries in working towards their NDCs in advance of the first stocktake scheduled for 2023. It is hoped that opening up the discussion to include non-government actors and allowing shared experiences will strengthen action. Regardless of this support, most NDCs are not yet ambitious enough to meet the agreed temperature targets; analysis shows that only a small number of countries have mitigation commitments that will limit warming to below $2{ }^{\circ} \mathrm{C}$ and only a couple are on track for the $1.5^{\circ} \mathrm{C}$ target (https:// climateactiontracker.org).

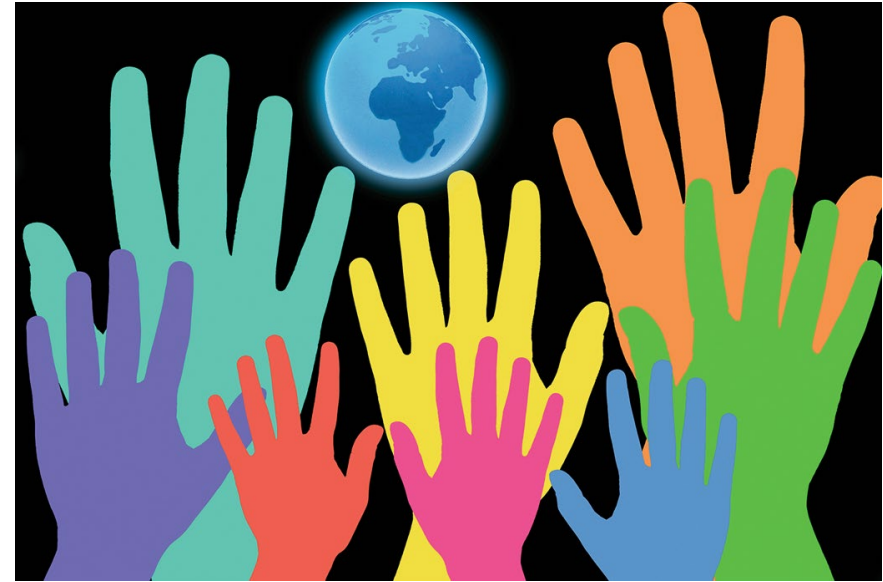

Credit: Emilio Ereza/Alamy Stock Photo

Making a mitigation commitment is important, but this also needs to be achieved, which can be challenging. A German government report released this last month states that they are not likely to meet the commitments made under the 2020 target of a $40 \%$ reduction in GHGs (relative to 1990 levels). The report projects that a $32 \%$ reduction will be achievable, as there has been unexpected strong population growth and economic growth. Preparing for the unexpected, whether that be changes in economic prosperity, population shifts (as seen in Germany), the political environment, technological advances or the emergence of climate change signals, is required to stay on track with mitigation efforts.

Higher ambition requires greater investment, with a predicted US $\$ 460$ billion of investment in the low-carbon economy needed to achieve the lower temperature target ${ }^{3}$. Large investments in renewables, as Germany has done with its Energiewende (energy transition, http:// www.energiewende-global.com/en), and low carbon technologies such as energy storage and transmission, are needed to attain the $1.5^{\circ} \mathrm{C}$ target. Finance will play an important role in the transition away from fossil fuel dependence, which will also present financial risks; in this issue Mercure et al. estimate that stranded fossil fuel assets may be worth trillion of dollars. A combination of climate policies and lower fossil fuel demand due to more efficient technologies results in unrealized investments in fossil fuel reserves and subsequent financial losses.
Taking action earlier could reduce economic damages, with a recent study ${ }^{4}$ predicting US $\$ 30$ trillion in cumulative benefits from limiting warming to $1.5^{\circ} \mathrm{C}$, relative to $2{ }^{\circ} \mathrm{C}$ - far outweighing the costs of mitigation action. This is just one of many recent studies that considers what a $1.5^{\circ} \mathrm{C}$ world would be like. A remarkable amount of work has been done, and a corresponding literature generated, in the two and a half years since $1.5^{\circ} \mathrm{C}$ became a target (see the evolving Targeting $1.5^{\circ} \mathrm{C}$ collection, which highlights papers published across the Nature Research Group for a snippet of the literature; www.nature.com/1.5Ctarget). This body of work has all been feeding into the IPCC Special Report on global warming of $1.5^{\circ} \mathrm{C}$, which was requested at the time of the Paris Agreement, and is now with governments for final review before completion. The report is a testament to the research community's commitment to supporting international ambition through generating data on the issue.

The road ahead is challenging, as can be seen from the hurdles that have arisen over recent years - the spirit captured at the time of the Paris Agreement shows that together there is strength.

Published online: 29 June 2018 https://doi.org/10.1038/s41558-018-0223-9

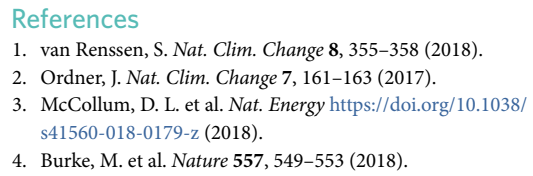

